Revista Energia na Agricultura

ISSN 1808-8759

\title{
EFEITO DE PARÂMETROS VARIÁVEIS DE FERMENTAÇÃO SOBRE O CRESCIMENTO CELULAR E COMPOSIÇÃO QUÍMICA DO FERMENTADO DE BATATA-DOCE ${ }^{\mathbf{1}}$ LIZANDRA BRINGHENTI ABUJAMRA ${ }^{2} \&$ CLAUDIO CABELLO $^{3}$
}

RESUMO: Este trabalho teve por objetivo avaliar o uso da batata-doce como substrato para a produção de bebida destilada. No sentido de promover uma alternativa tecnologicamente viável, traçou-se um planejamento experimental que minimizasse as operações de preparo, definindo as condições mais adequadas para o processo fermentativo. A partir da farinha de batata doce obtida por processo de desidratação e moagem das raízes foi realizado um processo enzimático de hidrólise-sacarificação de suspensão da farinha de batata-doce com $18 \%$ de matéria seca. O hidrolisado obtido foi utilizado no processo fermentativo que seguiu o planejamento experimental fatorial completo $2^{3}$ com pontos centrais e axiais, sendo as variáveis independentes a concentração de açúcares redutores, concentração de leveduras viáveis e temperatura da fermentação. As variáveis dependentes foram células viáveis, açúcares residuais, etanol, glicerol e metanol. As variáveis dependentes foram quantificadas por cromatografia líquida. A análise dos dados permitiu indicar que as melhores condições de fermentação dentre as condições testadas foram: concentração de leveduras $5 \times 10^{7}-1 \times 10^{8}$ em número de células viáveis, açúcares redutores totais de 12,5-13,5\% e temperatura entre $33-34^{0} \mathrm{C}$.

Palavras-chave: Álcool, amiláceo, fermentação.

\footnotetext{
${ }^{1}$ Parte da tese de doutorado da $1^{\circ}$ autora intitulada: " Produção de destilado alcoólico a partir de mosto fermentado de batata-doce."

${ }^{2}$ Aluna do Curso de PG Energia na Agricultura - FCA/UNESP - Botucatu/SP - Brasil.

${ }^{3}$ Orientador e vice - diretor do CERAT- FCA/UNESP - Botucatu/SP - Brasil.
} 


\section{EFFECT OF VARIABLES FERMENTATION PARAMETERS ON CELULAR GROWTH AND CHEMICAL COMPOSITION OF SWEET POTATO FERMENTED}

SUMMARY: This study aimed to evaluate the use of sweet potato as a substrate for the production of spirits. In order to promote an alternative technologically feasible, an experimental design was performed to minimize the operations of preparation, defining the most adequate conditions for the fermentation process. From sweet potato flour obtained by milling and dehydration process of the roots was carried out an enzymatic process of hydrolysis-saccharification of suspension of sweet potato flour with $18 \%$ dry matter. The hydrolyzate was used in the fermentation process which followed the $2^{3}$ full factorial experimental design with central and axial points, and the independent variables were the concentration of reducing sugars, concentration of viable yeast and fermentation temperature. The dependent variables were viable cells, residual sugar, ethanol, glycerol and methanol. The dependent variables were quantified by liquid chromatography. The data analysis indicate that the best fermentation conditions among the tested conditions were: concentration of yeast $5 \times 10^{7}-1 \times 10^{8}$ in number of viable cells, total reducing sugars from 12.5 to $13.5 \%$ and temperature between $33-34^{\circ} \mathrm{C}$.

Keywords: Alcohol, starchy, fermentation.

\section{INTRODUÇÃO}

A cultura da batata doce é muito popular, sendo cultivada em todas as regiões do país. Embora seja utilizada pouca tecnologia nesta cultura, seus índices de produtividade têm aumentado. Este fato, aliado ao conhecimento do processo de hidrólise enzimática dos amidos, torna possível um processo seguro e acessível, propiciando a transformação desta matéria-prima numa bebida destilada.

O alicerce desta nova proposta necessita de embasamento tecnológico específico, pois, assim como no mercado da aguardente de qualidade, as possibilidades de comercialização e exportação estão cada vez mais exigindo que o processo de fabricação seja baseado em práticas criteriosamente determinadas para a obtenção de um produto padronizado. (CARDOSO, 2001). Dentro deste contexto, vislumbra-se uma série de oportunidades para a produção de destilados de outras matérias-primas, como a 
batata-doce, beneficiando os produtores rurais e incrementando toda sua cadeia produtiva. A industrialização agregaria valor ao produto.

O objetivo deste trabalho foi avaliar a batata-doce como substrato para produção de um destilado alcoólico, considerando a produção de compostos secundários e estabelecendo as melhores condições para a produção piloto do destilado.

\section{MATERIAL E MÉTODOS}

\subsection{Matéria-Prima}

Utilizou-se a batata-doce tipo Brazilânia Roxa de polpa branca adquirida de um produtor rural da cidade de Duartina/SP, a qual foi processada no máximo 24h após a sua aquisição.

Uma partida contendo $100 \mathrm{~kg}$ de batata-doce, adquirida em março/2008, foi lavada em água corrente e em seguida triturada em máquina de produzir raspas de mandioca. As raspas foram coletadas em bandejas metálicas e em seguida colocadas em estufa de circulação de ar, marca Marconi modelo MA037, para secagem a uma temperatura de $50^{\circ} \mathrm{C}$ por $24 \mathrm{~h}$. Após este tempo, a temperatura foi elevada para $105^{\circ} \mathrm{C}$ por mais $48 \mathrm{~h}$. Durante a secagem, o material foi revolvido no mínimo 2 vezes a cada $24 \mathrm{~h}$.

As raspas de batata-doce secas foram moídas num moinho de faca, marca Marconi modelo MA680 com tela de vazamento de 16 mesh $(\simeq$ 1,0mm). Após a moagem, o lote de material foi homogeneizado por agitação e armazenado em sacos plásticos de PVC em porções de 1,5kg.

\subsection{Processo de hidrólise sacarificação}

Num reator encamisado com controle eletrônico de temperatura e agitação da marca Ranazzi, com capacidade de $20 \mathrm{~L}$, foi preparada uma suspensão de $15 \mathrm{~L}$ com $18 \%$ de matéria seca utilizando $2,87 \mathrm{~kg}$ de farinha de batata doce, com umidade de 5,99\% e 12,13L de água. Adicionou-se 0,04g de $\mathrm{CaCl}_{2}$. No processo de hidrólise, utilizou-se a enzima $\alpha$-amilase $(0,5 \mathrm{~g} / \mathrm{kg} \mathrm{m} . \mathrm{s})$ na etapa de hidrólise e amiloglucosidase $2,0 \mathrm{~g} / \mathrm{kg}$ m.s na etapa de sacarificação. O período total do processo foi de $18 \mathrm{~h}$, sendo $2 \mathrm{~h}$ para a primeira enzima à $90^{\circ} \mathrm{C}$ e após o resfriamento e correção do $\mathrm{pH}$, mais $16 \mathrm{~h}$ com a segunda enzima à $60^{\circ} \mathrm{C}$. 
O hidrolisado obtido foi caracterizado quanto ao perfil de açúcares em cromatógrafo líquido, marca Varian modelo Pró-Star com duas bombas binárias e índice de refração (detector) com amostrador automático. A coluna da marca BIORAD modelo AMINEX HPX 87P (fase estacionária Pb) 300 x 0,25mm, utilizando como fase móvel água e fluxo da amostra de $0,6 \mathrm{ml} /$ minuto, na temperatura de $80^{\circ} \mathrm{C}$, o que permitiu a quantificação de sacarídeos de grau de polimerização $(\mathrm{Dp})$ de 1 a 9. Os perfis em área foram convertidos em concentração (g/L) a partir de curvas padrões.

\subsection{Ensaios de fermentação com hidrolisados}

\subsubsection{Planejamento experimental}

Um planejamento experimental composto central rotacional $2^{3}$, foi utilizado para verificar os efeitos das variáveis independentes sobre as variáveis dependentes. Foram realizados 20 tratamentos, sendo 8 fatoriais; 6 axiais; e 6 centrais (COCHRAN \& COX, 1957). Na determinação dos valores máximos e mínimos de cada variável independente foram considerados valores médios normalmente utilizados em processos fermentativos para a produção de cachaça.

Tabela 1 - Variáveis independentes e níveis das variáveis no planejamento experimental de fermentação.

\begin{tabular}{|c|c|c|c|c|c|c|c|}
\hline \multirow{2}{*}{$\begin{array}{l}\text { Variáveis indepen- } \\
\text { dentes }\end{array}$} & \multirow[t]{2}{*}{ Símbolo } & \multirow[t]{2}{*}{ Unidade } & \multicolumn{5}{|c|}{ Nível } \\
\hline & & & $-\alpha$ & -1 & 0 & +1 & $+\alpha$ \\
\hline $\begin{array}{c}\text { Concentração de } \\
\text { leveduras }\end{array}$ & Lev & $\%$ & 1,3 & 2 & 3 & 4 & 4,7 \\
\hline Temperatura & Temp & ${ }^{\circ} \mathrm{C}$ & 24,9 & 27 & 30 & 33 & 35,12 \\
\hline $\begin{array}{c}\text { Açúcares Reduto- } \\
\text { res }\end{array}$ & AR & $\%$ & 10,3 & 11 & 12 & 13 & 13,7 \\
\hline
\end{tabular}


Como variáveis dependentes foram avaliadas no vinho, após o término da fermentação, a viabilidade celular, concentração de etanol, concentração de açúcares residuais, etanol e glicerol. A avaliação da concentração dos compostos secundários foi realizada no etanol obtido após destilação controlada.

A variável independente concentração de leveduras foi calculada no planejamento experimental através da porcentagem, e para fins de medida e comparação ao final do processo essas porcentagens foram expressas em números de células iniciais e finais.

\subsection{Processo de fermentação}

O hidrolisado obtido foi fracionado em porções de $500 \mathrm{~mL}$ e conduzidos em erlenmeyers de $1000 \mathrm{~mL}$ em shaker por um período de 16 horas nas condições de temperatura do delineamento experimental. Foram utilizadas leveduras desidratadas na forma da cepa Y - 904 produzidas pela AB Brasil S.A como inoculo nas concentrações do delineamento (Tabela 1).

\subsection{Análises do vinho}

\subsubsection{Determinação da viabilidade celular}

A viabilidade celular foi determinada com a utilização de azul de metileno para colorir as células de levedura. Efetuou-se a contagem em microscópio ótico através da câmara de Neubauer.

2.5.2 Determinação da concentração de açúcares residuais, etanol, metanol e glicerol

A amostra foi centrifugada a 12000 rpm durante 8 minutos e filtrada em membrana PVDF $0,22 \mu \mathrm{m}$, de $13 \mathrm{~mm}$ de diâmetro, hidrofílica. Para verificação das concentrações de açúcares residuais (maltose, frutose, glicose), glicerol, etanol e metanol; foram realizadas análises por cromatografia líquida de alta resolução, em equipamento Varian, modelo Pró-Star 410, com detector de índice de refração,com coluna da Biorad modelos: i) HPX-87H na determinação de álcoois, utilizando temperatura de $50^{\circ} \mathrm{C}$, como fase móvel o ácido sulfúrico $0,01 \mathrm{M}$ e a vazão de $0,7 \mathrm{~mL} / \mathrm{min}$; ii) HPX-87P para determinação de glicose, maltose, sacarose, e outros oligossacarídeos, utilizando-se a temperatura de $85^{\circ} \mathrm{C}$, fase móvel a água deionizada e vazão de $0,6 \mathrm{~mL} / \mathrm{min}$. A identificação e quantificação das substâncias foram realizadas por comparação com cromatogramas de substâncias padrões injetadas nas mesmas condições. 


\subsection{Análise dos dados}

A Metodologia de Superfície de Resposta descreve o comportamento de um sistema no qual estão combinadas as variáveis independentes $\left(\mathrm{X}_{\mathrm{k}}\right)$ e a variável dependente ou resposta $\left(\mathrm{Y}_{\mathrm{i}}\right)$. A resposta é uma função dos níveis nos quais estes fatores foram combinados e definidos.

Dentro das faixas de variação propostas, ou seja, dentro da região caracterizada por esses níveis, o comportamento de cada resposta pode ser predito de forma generalizada de acordo com a Equação 2:

$$
Y_{1}=\beta_{o}+\beta_{1} X_{1}+\beta_{2} X_{2}+\beta_{3} X_{3}+\beta_{11} X_{1}^{2}+\beta_{22} X_{2}^{2}+\beta_{33} X_{3}^{2}+\beta_{12} X_{1} X_{2}+\beta_{13} X_{1} X_{3}+\beta_{23} X_{2} X_{3+} \varepsilon
$$

Onde:

$Y_{1}=$ Variável dependente ou função resposta;

$\mathrm{X}_{1}, \mathrm{X}_{2}, \mathrm{X}_{3}=$ Valores das variáveis independentes;

$\beta_{o}=$ Coeficiente relativo à interceptação do plano com o eixo resposta;

$\beta_{1}, \beta_{2}, \beta_{3}=$ Coeficientes lineares estimados pelo método dos mínimos quadrados;

$\beta_{11}, \beta_{22}, \beta_{33}=$ Coeficientes das variáveis quadráticas;

$\beta_{12}, \beta_{13}, \beta_{23}=$ Coeficientes de interação entre as variáveis independentes;

$\varepsilon=$ Erro experimental.

O ajuste do modelo foi feito pela opção "stepwise" do programa SAS, sendo que o modelo obtido foi validado pelo teste $\mathrm{F}$ utilizando-se como denominador o quadrado médio do erro puro.

As superfícies de resposta foram construídas utilizando-se o software STATISTICA versão 5.5. $\mathrm{Na}$ construção das superfícies, uma das variáveis independentes foi mantida fixa no ponto central, enquanto as outras duas variaram dentro das regiões propostas no planejamento.

\section{RESULTADOS E DISCUSSÃO}

A análise do hidrolisado mostrou a presença de $13,7 \%$ de açúcares totais em $12,5 \mathrm{~kg}$ do hidrolisado.

Os resultados obtidos nas análises do vinho nas diferentes condições experimentais estão apresentadas na Tabela 2. A análise estatística dos dados mostrou influência significativa da concentração inicial de leveduras e da temperatura de fermentação sobre o crescimento celular. (Tabela 3)

Os maiores valores de crescimento celular foram encontrados nas faixas onde a concentração inicial de leveduras foi $1,2 \times 10^{8}-1,3 \times 10^{8}$, em todas as temperaturas testadas, conforme a Figura 1. Estes 
dados estão alinhados com Lima (2001), que cita as temperaturas ótimas para a produção industrial de etanol as situadas na faixa de $26-35^{\circ} \mathrm{C}$. Entretanto, considerando o equilíbrio entre a multiplicação celular e produção de etanol é possível observar como melhores condições a concentração inicial de leveduras na faixa de $4 \times 10^{7}$ a $1 \times 10^{8}$.

Tabela 2 - Condições experimentais para crescimento celular, maltose, sacarose, glicose, glicerol e etanol e metanol:

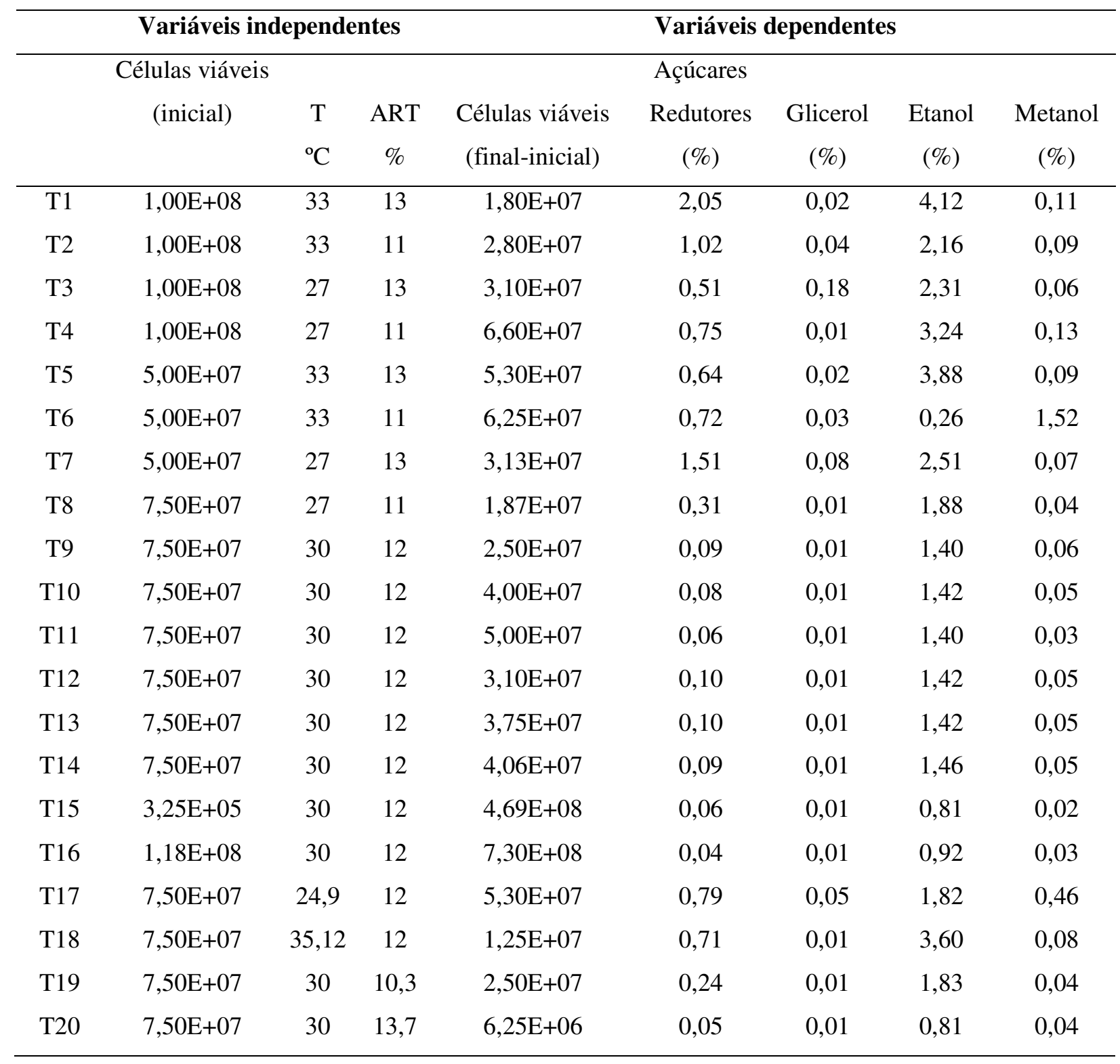


Tabela 3 - Coeficientes de regressão estimados e ANOVA para a taxa de crescimento celular (txcel) no processo de fermentação de hidrolisado de batata doce.

\begin{tabular}{|c|c|c|c|c|}
\hline & $\begin{array}{l}\text { Coeficientes de } \\
\text { regressão }\end{array}$ & Erro padrão & GL & $p$ valor \\
\hline Média & 10822115 & & & \\
\hline Levedura (quadrático) & 164749091 & 25702504 & 1 & $<0,0001$ \\
\hline Temperatura (quadrático) & -50414684 & 25702504 & 1 & 0,0664 \\
\hline $\mathrm{R}^{2}$ & 0,7368 & & & \\
\hline \multicolumn{5}{|l|}{ ANOVA } \\
\hline GL & SQ & QM & $\mathrm{F}$ valor & $\operatorname{Pr}>\mathrm{F}$ \\
\hline Regressão & 4,578244E17 & $2,289122 \mathrm{E} 17$ & 23,80 & $<0,0001$ \\
\hline Resíduos & $1,635217 \mathrm{E} 17$ & $9,618924 \mathrm{E} 15$ & & \\
\hline Total & $6,213462 \mathrm{E} 17$ & & & \\
\hline
\end{tabular}

Efeitos significativos $\mathrm{p}<0,05$; efeito significativo $\mathrm{p}<0,10$

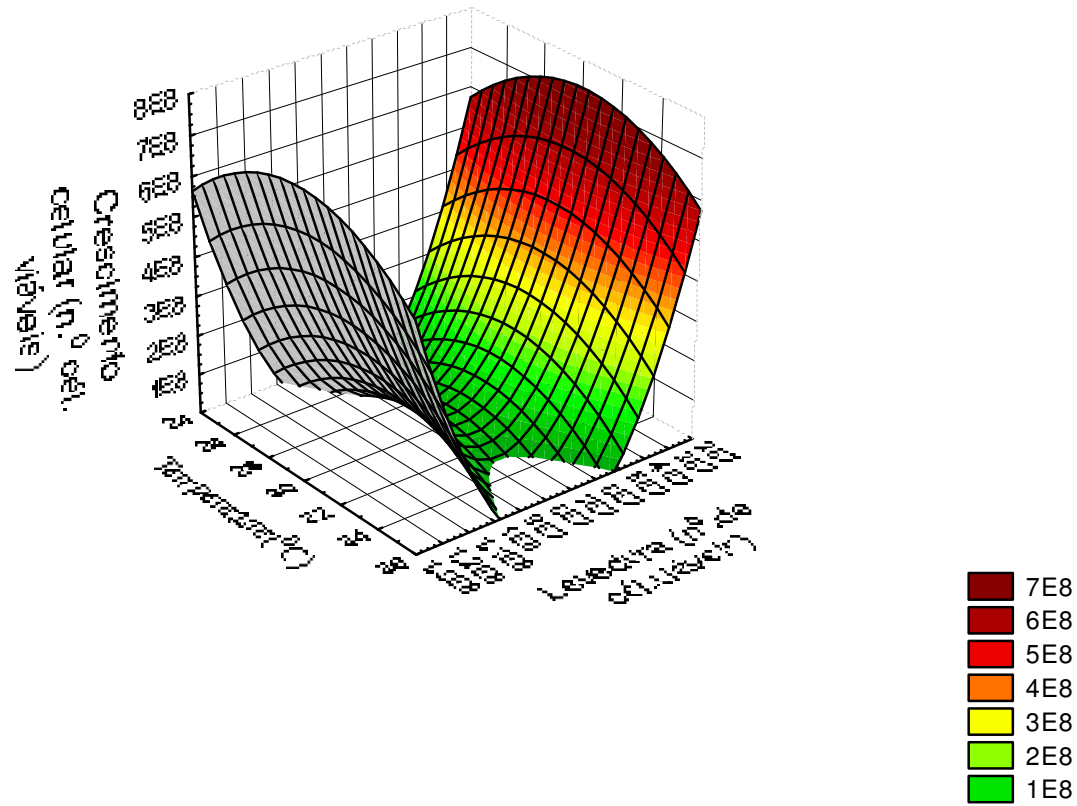

Figura 1 - Efeito da temperatura e concentração de leveduras sobre o crescimento celular, com o teor de açúcares de $12 \%$. 


\subsection{Glicose}

A glicose apresentou valores de concentração entre 0,02 e $0,18 \%$ como valores mínimos e máximos respectivamente (Tabela 2). A análise de regressão mostrou efeito significativo $(p<0,05)$ dos fatores analisados sobre a glicose (Tabela 5). Os menores resultados residuais de glicose foram obtidos quando a concentração de açúcares redutores inicial estava na faixa de 11 a $13 \mathrm{~g} \cdot \mathrm{L}^{-1}$ e a temperatura entre 26 e $34^{0} \mathrm{C}$. (Figura 2) Esta concentração de açúcares não produz alterações drásticas na resposta das leveduras devido ao estresse osmótico que segundo Hohmann (1977), produz uma perda da quantidade de água intracelular. Quando os parâmetros analisados foram a temperatura e a concentração de leveduras, os melhores resultados para a glicose residual $(0-0,12 \%)$ foram obtidos nas faixas de temperatura de 26 a $34^{0} \mathrm{C}$ e concentração inicial de leveduras entre $2 \times 10^{7}-1 \times 10^{8}$. Na Figura 3 observa-se que as melhores condições seriam para concentrações iniciais na faixa de 11 a 13 g. $\mathrm{L}^{-1}$ e concentração de leveduras de $2 \times 10^{7}$ a $1 \times 10^{8}$.

Tabela 5 - Coeficientes de regressão estimados e ANOVA para glicose.

\begin{tabular}{|c|c|c|c|c|c|}
\hline & & $\begin{array}{l}\text { Coeficientes de } \\
\text { regressão }\end{array}$ & Erro padrão & GL & $p$ valor \\
\hline \multicolumn{2}{|l|}{ Média } & 0,0203 & & & \\
\hline \multicolumn{2}{|c|}{ Levedura (linear) } & 0,0205 & 0,0116 & 1 & 0,0952 \\
\hline \multicolumn{2}{|c|}{ Temperatura (quadrático) } & 0,0167 & 0,0112 & 1 & 0,1543 \\
\hline \multicolumn{2}{|c|}{ AR (quadrático) } & 0,0238 & 0,0112 & 1 & 0,0494 \\
\hline \multicolumn{2}{|l|}{$\mathrm{R}^{2}$} & 0,3696 & & & \\
\hline \multicolumn{6}{|l|}{ ANOVA } \\
\hline & GL & SQ & QM & $\mathrm{F}$ valor & $\operatorname{Pr}>\mathrm{F}$ \\
\hline Regressão & 3 & 0,0171 & 0,0057 & 3,13 & 0,0551 \\
\hline Resíduos & 16 & 0,0292 & 0,0018 & & \\
\hline Total & 19 & 0,0463 & & & \\
\hline
\end{tabular}




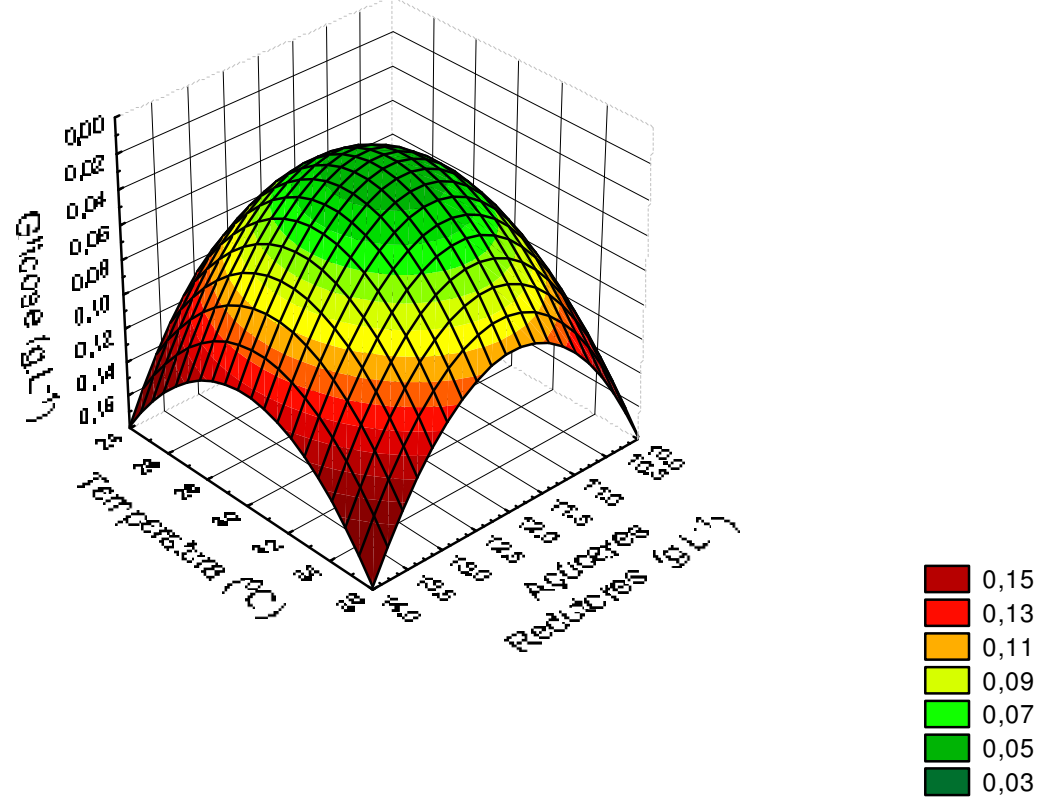

Figura 2 - Efeito da temperatura e concentração de glicose sobre o teor de açúcares redutores ao final dos processos, com a concentração de leveduras em 7,5X10 ${ }^{7}$.

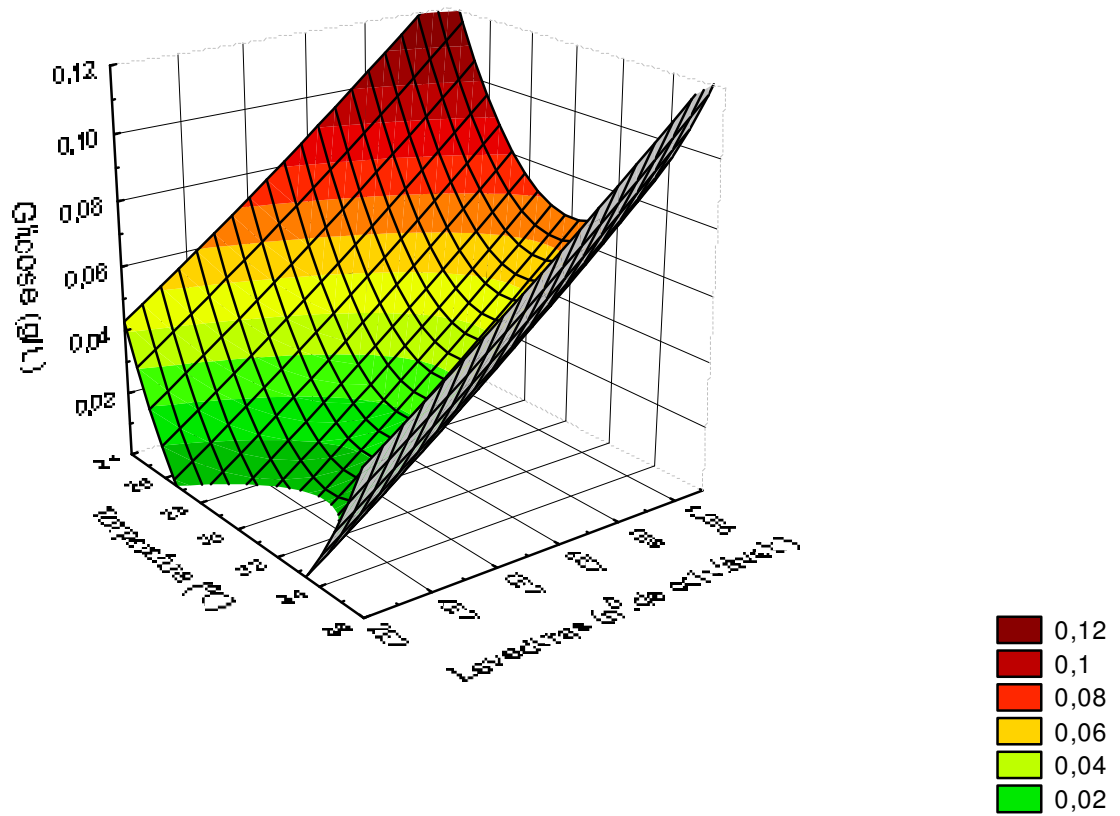

Figura 3 - Efeito da temperatura e concentração de levedura sobre o teor de glicose no vinho, com o teor de açúcares em $12 \%$. 


\subsection{Glicerol}

O glicerol apresentou valores de concentração entre 0,01 e 0,18 \% (Tabela 3). A análise de regressão mostrou efeito significativo $(\mathrm{p}<0,05)$ da temperatura e o AR sobre o glicerol (Tabela 6).

Tabela 6 - Coeficientes de regressão estimados e ANOVA para glicerol.

\begin{tabular}{|c|c|c|c|c|c|}
\hline & & $\begin{array}{l}\text { Coeficientes de } \\
\text { regressão }\end{array}$ & Erro padrão & GL & $p$ valor \\
\hline \multicolumn{2}{|l|}{ Média } & 0,0275 & & & \\
\hline \multicolumn{2}{|c|}{ Temperatura (linear) } & $-0,0174$ & 0,0081 & 1 & 0,0475 \\
\hline \multicolumn{2}{|l|}{ AR (linear) } & 0,0154 & 0,0081 & 1 & 0,0756 \\
\hline \multicolumn{2}{|c|}{ Temperatura x AR } & $-0,0338$ & 0,0106 & 1 & 0,0057 \\
\hline \multicolumn{2}{|l|}{$\mathrm{R}^{2}$} & 0,5350 & & & \\
\hline \multicolumn{6}{|l|}{ ANOVA } \\
\hline & GL & SQ & QM & F valor & $\operatorname{Pr}>\mathrm{F}$ \\
\hline Regressão & 3 & 0,0165 & 0,0055 & 6,14 & 0,0056 \\
\hline Resíduos & 16 & 0,0143 & 0,0009 & & \\
\hline Total & 19 & 0,0308 & & & \\
\hline
\end{tabular}

Os maiores valores de glicerol são obtidos a condições de baixa temperatura e elevado teor de açúcares, bem como, nos seus inversos (Figura 4). Hohmann (1977) verificou ser o glicerol um protetor efetivo contra o efeito da osmolaridade em leveduras. Os resultados condizem com Gutierrez (1991), onde afirmou, que dentre outros fatores a formação de glicerol é fortemente influenciada pela temperatura e concentração de açúcares. 


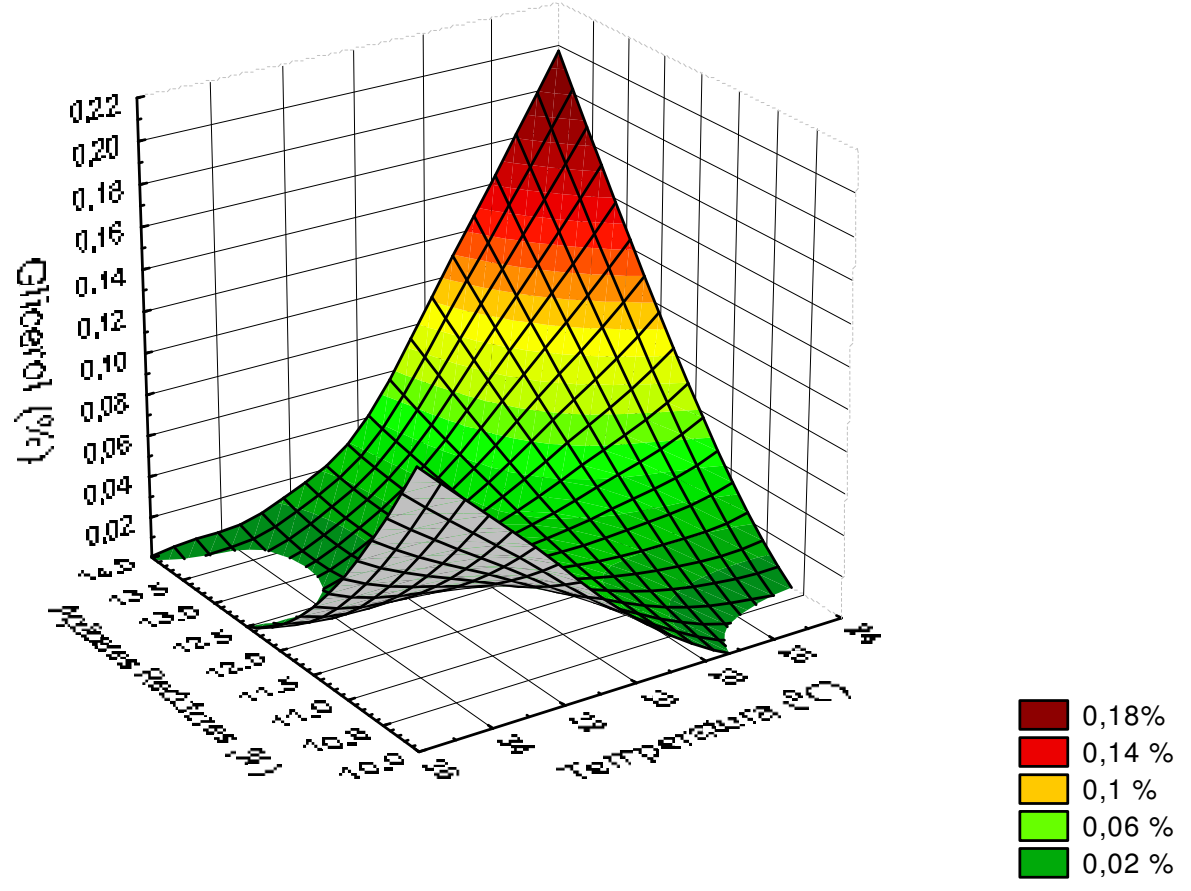

Figura 4 - Efeito da temperatura e teor de açúcares redutores sobre o teor de glicerol, com a concentração de leveduras o eixo central $\left(7,5 \times 10^{7}\right)$.

\subsection{Etanol}

Os teores de etanol produzidos se situaram nas concentrações entre 0,56 e 4,12 \%. (Tabela 3) A análise de regressão mostrou efeito significativo $(\mathrm{p}<0,05)$ da temperatura e o AR sobre o etanol. (Tabela 7) Através da superfície de resposta (Figura5) observou-se que nas condições de temperaturas mais baixas, 24 a $28^{0} \mathrm{C}$, a maior produção de etanol ocorreu com concentrações iniciais de AR entre 10 e 11,5g;L. O inverso foi verdadeiro, ou seja, quando as concentrações de AR estavam entre 12 e $14 \mathrm{~g} . \mathrm{L}^{-1}$ as maiores produções de etanol foram obtidas com temperaturas entre 33 e $35^{\circ} \mathrm{C}$. A concentração de etanol de 56,6 g. $\mathrm{L}^{-1}$ inibe o crescimento celular tornando a membrana celular permeável a prótons e conseqüentemente acidificando o seu citoplasma. A célula produz trealose e afeta a produtividade em etanol. (D`AMORE; STEWART,1987) 


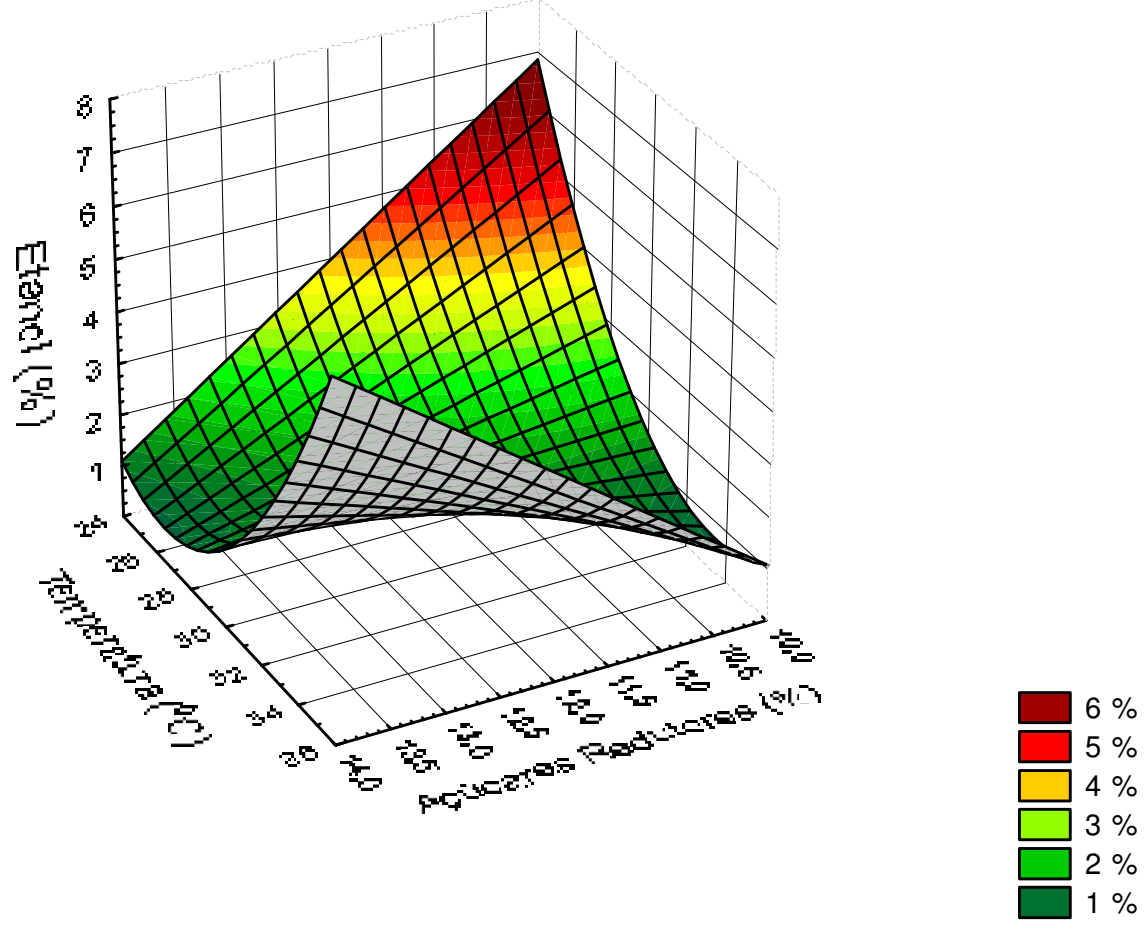

Figura 5- Efeito da temperatura e teor de açúcares redutores sobre o teor de etanol, com a concentração de leveduras $\left(7,5 \times 10^{7}\right)$.

\subsection{Metanol}

O metanol pode ser produzido durante os estágios da fermentação, entretanto, é um composto indesejável ao produto final, devido a sua alta toxicidade. $\mathrm{O}$ teor de metanol variou entre 0,02 e $0,52 \%$ (Tabela3). A análise de regressão mostrou não ter ocorrido efeito significativo dos fatores analisados sobre o metanol (Tabela 7). 
Tabela 7- Coeficientes de regressão estimados e ANOVA para metanol.

\begin{tabular}{|c|c|c|c|c|c|}
\hline & & $\begin{array}{l}\text { Coeficientes de } \\
\text { regressão }\end{array}$ & Erro padrão & GL & $p$ valor \\
\hline \multicolumn{2}{|l|}{ Média } & 0,0435 & & & \\
\hline \multicolumn{2}{|c|}{ Levedura (linear) } & $-0,9614$ & 0,0801 & 1 & 0,2577 \\
\hline \multicolumn{2}{|c|}{ Temperatura (linear) } & 0,0637 & 0,0801 & 1 & 0,4446 \\
\hline \multicolumn{2}{|l|}{ AR (linear) } & $-0,1061$ & 0,0801 & 1 & 0,2146 \\
\hline \multicolumn{2}{|c|}{ Levedura (quadrático) } & 0,0230 & 0,0779 & 1 & 0,7738 \\
\hline \multicolumn{2}{|c|}{ Temperatura (quadrático) } & 0,1096 & 0,0779 & 1 & 0,1900 \\
\hline \multicolumn{2}{|c|}{ AR (quadrático) } & 0,0283 & 0,0779 & 1 & 0,7239 \\
\hline \multicolumn{2}{|c|}{ Levedura $\mathrm{x}$ Temperatura } & $-0,1862$ & 0,1047 & 1 & 0,1055 \\
\hline \multicolumn{2}{|c|}{ Levedura $x$ AR } & 0,1687 & 0,1047 & 1 & 0,1380 \\
\hline \multicolumn{2}{|c|}{ Temperatura $\mathrm{x}$ AR } & $-0,1712$ & 0,1047 & 1 & 0,1329 \\
\hline \multicolumn{2}{|l|}{$\mathrm{R}^{2}$} & 0,588784 & & & \\
\hline \multicolumn{6}{|l|}{ ANOVA } \\
\hline & GL & SQ & QM & $\mathrm{F}$ valor & $\operatorname{Pr}>\mathrm{F}$ \\
\hline Regressão & 9 & 1,2549 & 0,1394 & 1,59 & 0,2397 \\
\hline Resíduos & 10 & 0,8764 & 0,0876 & & \\
\hline Total & 19 & 2,1314 & & & \\
\hline
\end{tabular}

\section{CONCLUSÕES}

Os parâmetros variáveis do processo influenciaram o crescimento celular, as produções de etanol, metanol, glicerol, bem como a presença de açúcares residuais. A condição de concentração de levedura em número de células viáveis de $5 \times 10^{7}-1 \times 10^{8}$, açúcares redutores iniciais de 12,5 - 13,5\% e temperatura de fermentação na faixa de $33-34^{0} \mathrm{C}$ permitiram a obtenção de fermentado de batata doce com maior teor de etanol, baixa concentração de açúcares residuais e baixos teores de metanol e glicerol. 


\section{REFERÊNCIAS}

CARDOSO, M. das G. Análises físico-químicas de aguardentes. In: (Ed.). Produção de aguardente de cana-de-açúcar. Lavras: Editora UFLA, 2001. cap. 5, p. 152-173.

COCHRAN, W.G.; COX, G.M. Experimental Designs. 2nd.ed. New York: John Wiley \& Sons, Inc., $1957,611 \mathrm{p}$.

D’AMORE.; T. STEWART, G. G. Ethanol tolerance of yeast. Enzyme Microbiology Techonology, Ontario, v. 9, p. $322-330,1987$.

GUTIERREZ, L. E. Produção de glicerol por linhagens Saccharomyces durante fermentação alcoólica. Anais da Escola Superior de Agricultura Luiz Queiroz, Piracicaba, v. 48, p. 55-69, 1991.

HOHMANN, S. Shaping up: the responses of yeast to osmotic stress. In: HOHMANN, S.; MAGER,W. H.( Eds.) Yeast stress responses. Heidelberg: Springer. 1977. p.101 - 134.

LIMA, U. A. et al. Processos fermentativos. In: Biotecnologia industrial: processos fermentativos e enzimáticos. São Paulo: Edgard Blucher, 2001. v. 3, p. 90-122. 